\title{
Effect of Inflation On Various Commodities
}

\author{
Lalitha Suddapally \\ CVR College of Engineering, Department of Management Studies, Ibrahimpatan, R.R.District, A.P., India \\ Email: lalitha.suddapally@ gmail.com.
}

\begin{abstract}
As we all know inflation rate refers to a general rise in prices measured against a standard level of purchasing power. This is discussed in the context of continuous rise of prices. When there is inflation, currency loses its purchasing power. This may be caused by either demand pull or cash push. In India inflation is measured based on the Wholesale Price Index (WPI), where as in developed countries like US, they use Consumer Price Index (CPI) as the basis. Presently in India, the index is calculated taking into account price levels of 1100 items and the year 2004-05 as base year. Inflation affects different categories of people in varying measures. Prices of some goods and services rise faster than others, where as for some goods and services, there may not be any remarkable change. The poor and the middle class suffer a lot because of continuous rise of prices as their wages and salaries are almost fixed. On the other hand, people with variable incomes benefit a lot out of it. In this paper it is attempted to study the influence of inflation on various commodity prices to understand how in real sense it is changing the consumption function. In this analysis it is revealed surprisingly that the prices of primary articles and food grains continually are increasing irrespective of variations in inflation. It is well known fact that for these basic needs only, major share of the income of poor and middle class people is spent. This means a continuous increase in burden on them. It is also observed that some commodity prices are varying in line with inflation and for some others no much variation is seen. From this study, it is felt that there is an immediate attention required to change the weight-ages given to various commodities in calculating the inflation to reflect reality.
\end{abstract}

Index Terms - Inflation, Wholesale Price Index, Consumer Price Index, Gross Domestic Product, commodity, needs, consumption function, weight-ages.

\section{INTRODUCTION}

Inflation implies a general increase in the prices measured against a general level of the power to purchase. The measure of inflation is obtained by comparing two sets of goods at different times. When there is inflation, the currency loses its purchasing power. For example, when Rs. 20 is the price of rice, with Rs. 100 one can purchase 5 $\mathrm{Kgs}$, if its price increases to Rs. 25 in the next period, with the same Rs. 100 only $4 \mathrm{Kgs}$ can be purchased. The computing for the increase in the cost, which is not reflected by increase in the quality, is carried out. There may be two causes for inflation. One demand pull i.e., excessive demand for the product and other is cash push i.e., decrease in supply of goods and increase in cost of factors of production. In India inflation is measured by the
Wholesale Price Index (WPI) but many developed countries like UK, US, Japan and China, use the Consumer Price Index (CPI) to calculate inflation. in India the Office of the Economic Adviser to the Government undertook to publish for the first time, an index number of wholesale prices, with base week ended August 19, $1939=100$, from the week commencing January 10, 1942. The index was calculated as the geometric mean of the price relatives of 23 commodities classified into four groups: (1) food \& tobacco; (2) agricultural commodities; (3) raw materials; and (4) manufactured articles. The price index is an indicator of the average price movement over time of a fixed basket of goods and services. . The WPI number is a weekly measure of wholesale price movement for the economy. WPI is based on Laspeyres formula. WPI is also the price index which is available on a shortest possible time lag i.e., two weeks. To ensure that the items in the index basket are as best representatives as possible, efforts are made to include all the important items transacted in the economy during the base year. The importance of an item in the free market will depend on its traded value during the base year. The National Statistical Commission has recommended that base year should be revised every five year and not later than ten years. The well known criteria for the selection of base year are (a) a normal year which is a year in which there are no abnormalities in the level of production, trade and in the price level and price variations, (b) a year for which reliable production, price and other required data are available and (c) a year as recent possible and comparable with other data series at national and state level. The base year at present is 2004-05 and the index calculation is based on 1,100 items instead of 435 used with the base year 1993-94.

\section{A. Calculation of WPI and Inflation Rate}

Let's calculate WPI for the year 2015 for a particular commodity, say rice. Assume that the price of a kilogram of rice in $2005=\mathrm{Rs} 20.00$ and in $2015=\mathrm{Rs}$ 40.00. The WPI of rice for the year 2015 is, (Price of rice in $2015-$ Price of rise in 2005)/ Price of rice in $2005 \times 100=(40-$ $20) / 20 \times 100=100$. Since WPI for the base year is assumed as 100 , WPI for 2015 will become $100+100=200$. In this way individual WPI values of the 1100 commodities are calculated and then the weighted average of individual WPI figures are found out to arrive at the overall WPI. Commodities are given weight-age depending upon its influence in the economy. The weight-ages that were given 
for primary commodities, fuel and ower and manufactured products respectively are $20.12 \%, 14.91 \%$ and $64.97 \%$. Now, if we have the WPI values of two time zones, say, beginning and end of year, the inflation rate for the year will be, (WPI of end of year - WPI of beginning of year)/WPI of beginning of year x 100. For example, WPI on Jan 1st 2015 is 200 and WPI of Jan 1st 2014 is 190 then inflation rate for the year 2015 is, $(200-190) / 190 \times 100=$ $5.26 \%$ and we say the inflation rate for the year 2015 is $5.26 \%$. This is how we get weekly inflation rates in India. Likewise monthly and yearly inflation rates also can be calculated [1].

\section{B. Factors influencing inflation}

$>$ When the government of a country print money in excess, prices increase to keep up with the increase in currency, leading to inflation.

$>$ Increase in production and labor costs, have a direct impact on the price of the final product, resulting in inflation.

$>$ When countries borrow money, they have to cope with the interest burden. This interest burden results in inflation.

$>$ High taxes on consumer products, can also lead to inflation.

$>$ Demands pull inflation, wherein the economy demands more goods and services than what is produced.

$>$ Cost push inflation or supply shock inflation, wherein non availability of a commodity would lead to increase in prices.

\section{Problems with inflation}

$>$ When the balance between supply and demand goes out of control, consumers could change their buying habits, forcing manufacturers to cut down production.

$>$ The mortgage crisis of 2007 in USA could best illustrate the ill effects of inflation. Housing prices increased substantially from 2002 onwards, resulting in a dramatic decrease in demand.

$>$ Inflation can create major problems in the economy. Price increase can worsen the poverty affecting low income household,

$>$ Inflation creates economic uncertainty and is a dampener to the investment climate slowing growth and finally it reduces savings and thereby consumption.

$>$ The producers would not be able to control the cost of raw material and labor and hence the price of the final product. This could result in less profit or in some extreme case no profit, forcing them out of business.

> Manufacturers would not have an incentive to invest in new equipment and new technology.

$>$ Uncertainty would force people to withdraw money from the bank and convert it into product with long lasting value like gold, artifacts.

\section{Discussion AND ANALYsis}

Inflation affects people in varying measures. Prices of some goods and services rise faster than others, where as for some goods and services, there may not be any remarkable change. The poor and the middle class suffer a lot because of continuous rise of prices as their wages and salaries are almost fixed. On the other hand, people with variable incomes benefit a lot out of it. It changes the consumption function.

\section{A. Inflation trend in the last 4 years}

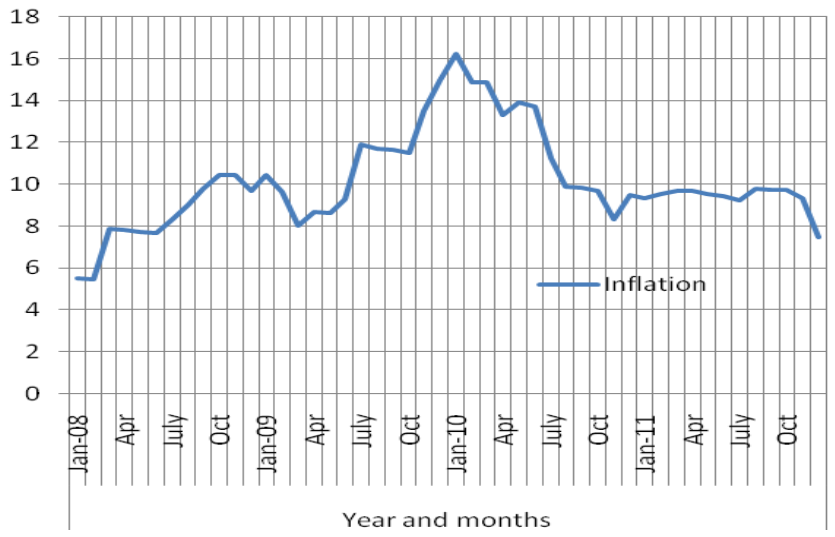

Figure 1. Inflation ( $\mathrm{Y}$ axis) for the last four years(X axis)

Inflation is observed to be very high from july, 2009 to july, 2010. It is below 10 only in all other months [2].

TABLE I.

INFLATION FOR THE LAST FOUR YEARS

\begin{tabular}{|c|c|c|c|c|c|c|c|c|c|c|c|c|}
\hline Year & Jan & Feb & Mar & Apr & May & June & July & Aug & Sept & Oct & Nov & Dec \\
\hline $\mathbf{2 0 1 1}$ & 9.35 & 9.54 & 9.68 & 9.70 & 9.56 & 9.44 & 9.22 & 9.78 & 9.72 & 9.73 & 9.34 & 7.47 \\
\hline $\mathbf{2 0 1 0}$ & 16.22 & 14.86 & 14.86 & 13.33 & 13.91 & 13.73 & 11.25 & 9.88 & 9.82 & 9.70 & 8.33 & 9.47 \\
\hline $\mathbf{2 0 0 9}$ & 10.45 & 9.63 & 8.03 & 8.70 & 8.63 & 9.29 & 11.89 & 11.72 & 11.64 & 11.49 & 13.51 & 14.97 \\
\hline $\mathbf{2 0 0 8}$ & 5.51 & 5.47 & 7.87 & 7.81 & 7.75 & 7.69 & 8.33 & 9.02 & 9.77 & 10.45 & 10.45 & 9.70 \\
\hline
\end{tabular}




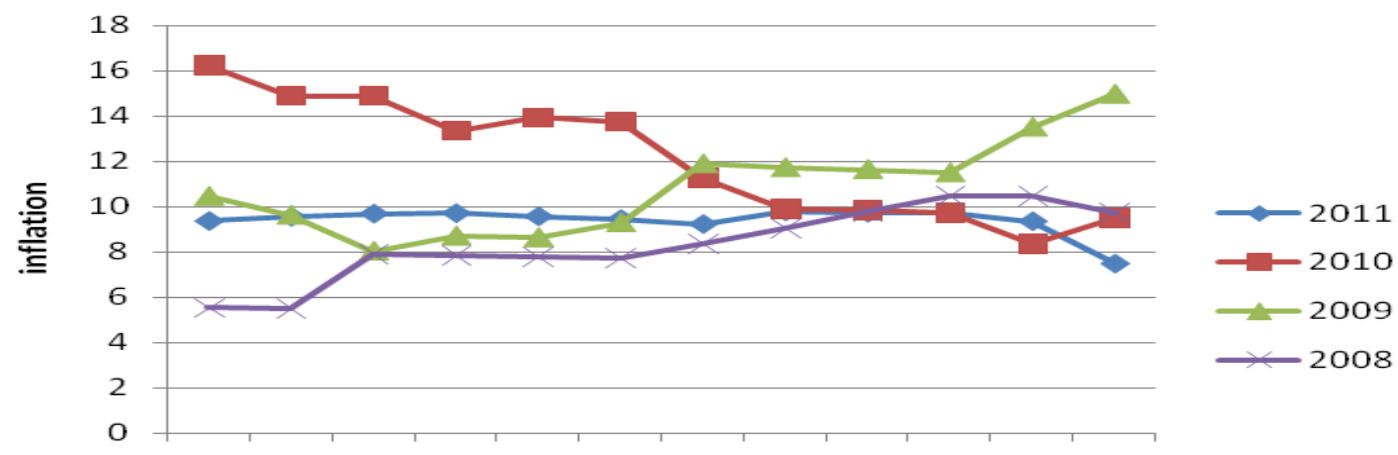

Jan Feb Mar Apr May June July Aug Sept Oct Nov Dec

months

Figure 2. Inflation year wise in the last four years

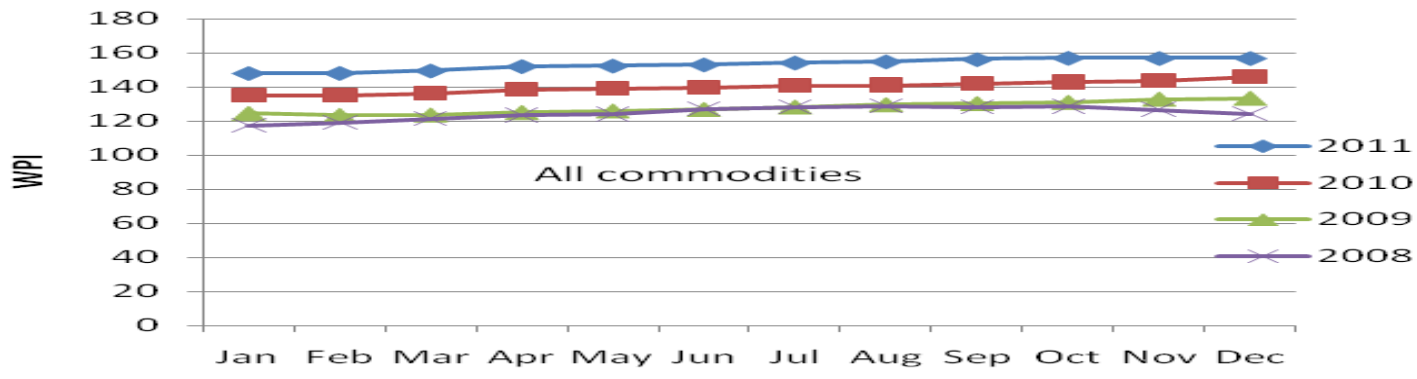

Months

Figure 3. WPI year wise for the last four years

TABLE II.

WPI FOR THE LAST FOUR YEARS (ALL COMMODITIES)

\begin{tabular}{|c|c|c|c|c|c|c|c|c|c|c|c|c|}
\hline Month/Year & Jan & Feb & Mar & Apr & May & Jun & Jul & Aug & Sep & Oct & Nov & Dec \\
\hline 2011 & 148 & 148.1 & 149.5 & 152.1 & 152.4 & 153.1 & 154.2 & 154.9 & 156.2 & 157 & 156.9 & 156.9 \\
\hline 2010 & 135.2 & 135.2 & 136.3 & 138.6 & 139.1 & 139.8 & 141 & 141.1 & 142 & 142.9 & 143.8 & 146 \\
\hline 2009 & 124.4 & 123.3 & 123.5 & 125 & 125.9 & 126.8 & 128.2 & 129.6 & 130.3 & 131 & 132.9 & 133.4 \\
\hline 2008 & 117.5 & 119 & 121.5 & 123.5 & 124.1 & 127.3 & 128.6 & 128.9 & 128.5 & 128.7 & 126.9 & 124.5 \\
\hline
\end{tabular}

From the above Table II.and Figures 2 and 3, one can easily understand that though there are continuous variations in inflation, there is a continuous increase in Wholesale Price Index year after year and also every month in every year. This indicates inflation calculated is not according to the patterns of WPI of all commodities.

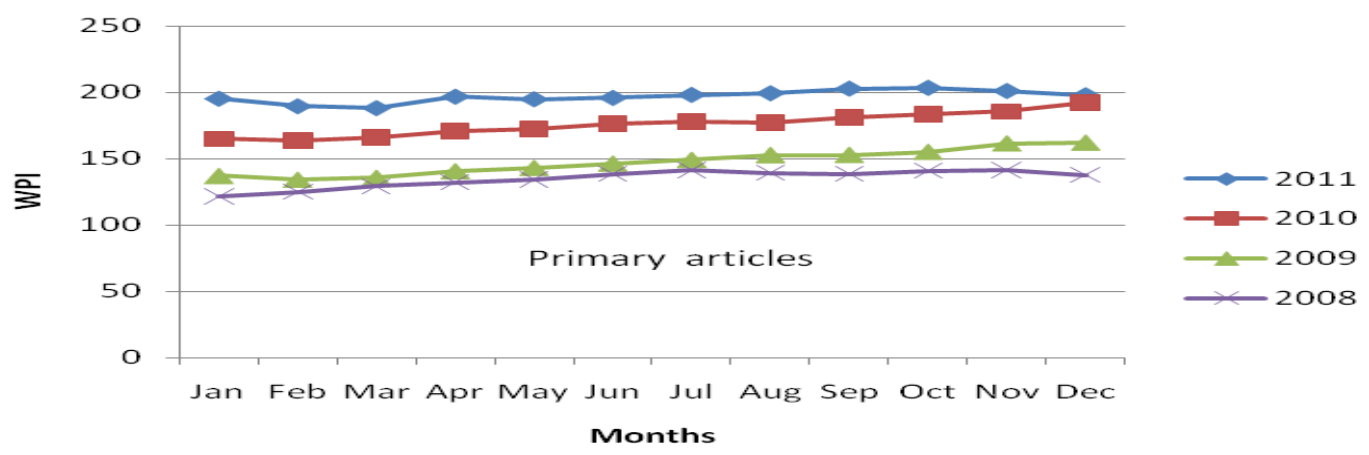

Figure 4. WPI of pimary articles for the last four years 


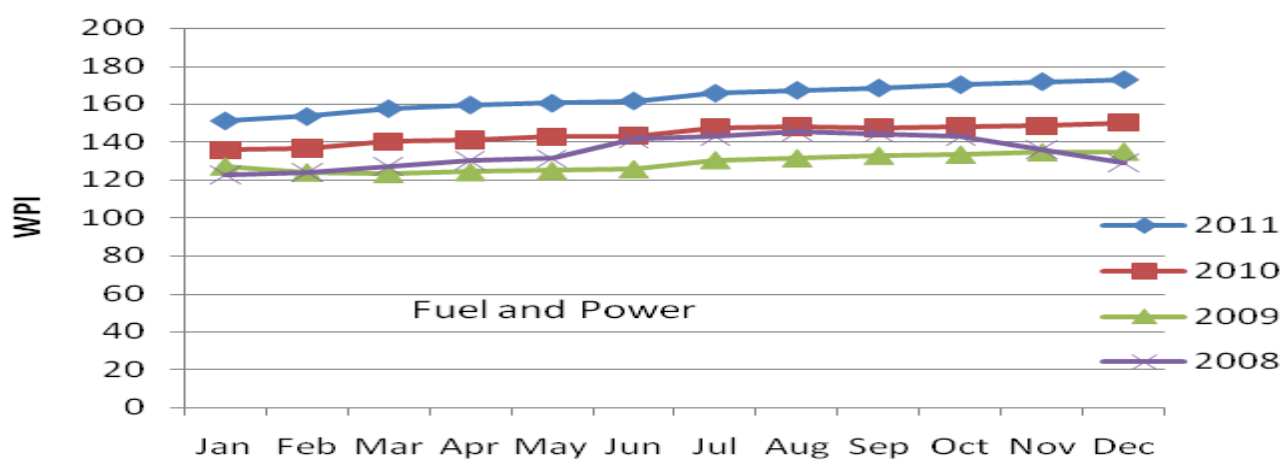

Months

Figure 5. WPI of fuel and power for the last four years

TABLE III.

WPI FOR THE LAST FOUR YEARS (PRIMARY ARTICLES)

\begin{tabular}{|c|c|c|c|c|c|c|c|c|c|c|c|c|}
\hline Month/Year & Jan & Feb & Mar & Apr & May & Jun & Jul & Aug & Sep & Oct & Nov & Dec \\
\hline 2011 & 195.3 & 189.6 & 188.2 & 196.8 & 194.9 & 195.9 & 198.2 & 199.4 & 202.9 & 203.5 & 201.1 & 197.9 \\
\hline 2010 & 164.9 & 163.6 & 165.9 & 171 & 172.6 & 176 & 177.8 & 177.3 & 180.8 & 183.4 & 185.3 & 192 \\
\hline 2009 & 137.2 & 134.4 & 135.8 & 140.8 & 143.3 & 146.5 & 149.3 & 152.9 & 153 & 155.3 & 161.6 & 162.2 \\
\hline 2008 & 121.2 & 124.8 & 128.9 & 132.1 & 134.2 & 138.3 & 141.1 & 139.2 & 138.3 & 140.8 & 141.4 & 137.5 \\
\hline
\end{tabular}

TABLE IV.

WPI FOR THE LAST FOUR YEARS (FUEL AND POWER)

\begin{tabular}{|c|c|c|c|c|c|c|c|c|c|c|c|c|}
\hline Month/Year & Jan & Feb & Mar & Apr & May & Jun & Jul & Aug & Sep & Oct & Nov & Dec \\
\hline 2011 & 151.3 & 153.5 & 157.6 & 159.5 & 160.4 & 161.6 & 165.6 & 167.1 & 168.3 & 170 & 171.6 & 172.6 \\
\hline 2010 & 135.8 & 136.6 & 140.1 & 141.1 & 142.8 & 143.2 & 147.8 & 148 & 147.6 & 148.1 & 148.6 & 150.2 \\
\hline 2009 & 127.2 & 124 & 123.1 & 124.2 & 124.8 & 125.7 & 130.5 & 131.5 & 132.9 & 133.4 & 134.7 & 135 \\
\hline 2008 & 122.8 & 124 & 127.4 & 130.2 & 131.4 & 141.7 & 143.2 & 145.6 & 144.6 & 143.1 & 136.2 & 129.1 \\
\hline
\end{tabular}

TABLE V.

WPI For THE LAST FoUR YeARS (MANUFACTURED PRODUCTS)

\begin{tabular}{|c|c|c|c|c|c|c|c|c|c|c|c|c|}
\hline Month/Year & Jan & Feb & Mar & Apr & May & Jun & Jul & Aug & Sep & Oct & Nov & Dec \\
\hline 2011 & 132.6 & 134 & 135.6 & 136.6 & 137.4 & 137.9 & 138 & 138.4 & 139 & 139.6 & 139.8 & 140.6 \\
\hline 2010 & 125.9 & 126.1 & 126.2 & 127.9 & 127.9 & 127.8 & 128.1 & 128.3 & 128.7 & 129.2 & 129.8 & 130.9 \\
\hline 2009 & 119.8 & 119.7 & 119.8 & 120.2 & 120.8 & 121 & 121.1 & 122 & 122.6 & 122.9 & 123.6 & 124.2 \\
\hline 2008 & 115.1 & 116 & 117.8 & 119.2 & 119.2 & 120.7 & 121.4 & 121.8 & 121.8 & 121.6 & 120.2 & 119.3 \\
\hline
\end{tabular}

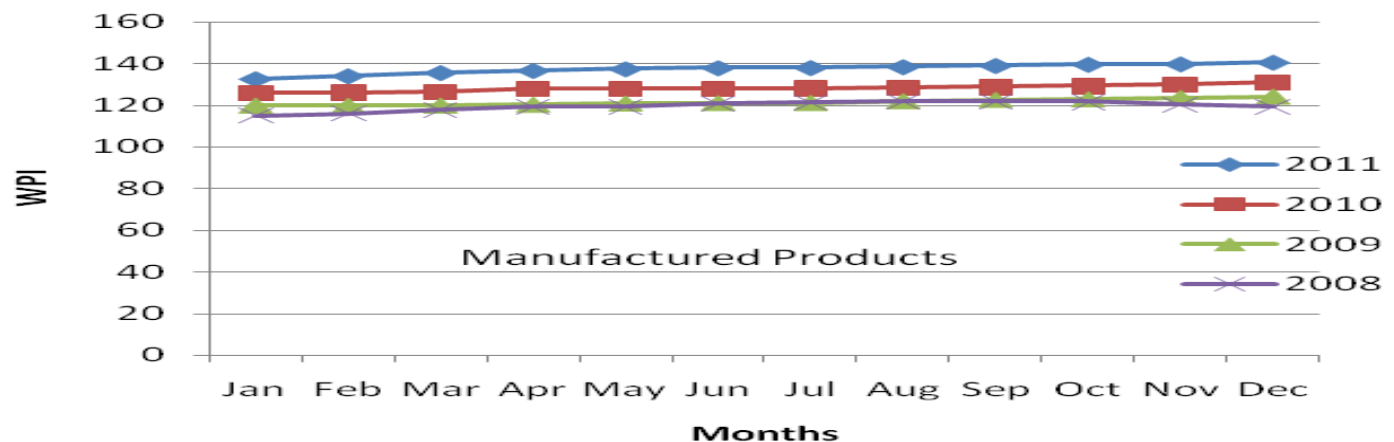


From the Tables II, III, IV and V, Figures 3, 4, 5 and 6, we can observe that the pattern of all commodities which are taken as a basis for the calculation of yearly inflation almost resembles the pattern of manufactured products for all the years. It may be because of the amount of weightage $(64.97 \%)$ given to it. That means the total results are influenced by this weight-age of manufactured products 64 , $97 \%$.

The WPI of all commodities are ranging from 117.5 to 156.9 and manufactured products are ranging from 115,1 to 140.6 which are close to each other. Whereas when we observe the primary articles and fuel \& power, these values are ranging from 121.2 to 197.9 and 122.8 to 172.6 respectively for the same period of time. This indicates the rate of increase in prices of primary articles and fuel \& power is very high compared to that of manufactured products. Further, the manufactured products are not letting the actual variation in the other two appear in the all commodity WPI and also in inflation calculations as it has major weight-age and is always below the other two.

As we all know, the primary articles include food articles like rice, jowar, ragi, tea, coffee, urad, vegetables, fruits, condiments, spices, mutton, chicken, pork, fish, egg, buffalo meat, bajra, masur, gram, wheat, milk etc., Nonfood articles like gaur seed, flowers, linseed, soya bean, rape and mustard seed, raw silk, sunflower and raw rubber, safflower, groundnut seed, niger seed, gingelly seed, fodder, cotton seed, castor seed, coir fiber, raw cotton and raw jute etc., and minerals like sillimanite, barites, iron ore, bauxite, dolomite, crude petroleum, magnetite, steatite, copper ore etc.

Fuel and power, include items such as electric power, petrol, naphtha, aviation fuel, light diesel oil, diesel, bitumen, furnace oil etc.

Manufactured products include food products like processed prawn, canned fish, salt, gingelly oil, sugar, mustard and rapeseed oil, groundnut oil, khandsari, palm oil, powder milk, gaur, oil cakes, mixed spices, tea dust, tea leaf, copra oil, wheat flour, ghee, beverages, coffee powder etc., Other items of manufactured products include, tobacco and tobacco products, textiles, wood and wood products, paper and paper products, leather and leather products, chemicals and chemical products, non-metallic mineral products, basic metals, alloys and metal products, transport equipment and parts etc.

From the above, we can easily understand that the first two categories are essential commodities and fulfill the basic needs of the all human beings. Whereas the manufactured products is mostly related to comforts and luxuries related items, which are mostly consumed by higher middle class and well to do class people. Though primary articles and fuel \& power are used by all the human beings, the amount of income spared for various items in their consumption function vary from poor, lower middle, higher middle and well to do class people. $70 \%$ $90 \%$ of the income of poor and middle class people is spared only for these two category items. Where as well to do class people spare less than $10 \%$ of their income for these two category of items. This means that when there is greater rise in prices of these two categories of items, well to do class has no much impact but the other two classes of people have to sacrifice their other needs to fulfill these essential basic requirements as their income levels are almost fixed.

In this regard, discussion about influence of rise of prices on private sector and government employees also should be done. Because, the income levels of private sector employees are more or less fixed as there is no mechanism in India to monitor the compensation for private sector employees for inflation. This is very much true particularly for poor and lower level employees of the private organizations who amount to more than $60 \%$ of population. For Government employees the Government announces DA to compensate the inflation influence on the cost of living. This is also based on the calculated inflation rates only which are not reflecting the reality because of more weight-age to manufactured products.

$$
\text { TABLE VI. }
$$

YEARLY WPI OF VARIOUS COMMODITIES FOR THE LAST 5 YEARS

\begin{tabular}{|c|c|c|c|c|c|c|}
\hline Cal & 2010 & 2009 & 2008 & 2007 & 2006 & 2005 \\
\hline $\begin{array}{l}\text { FOOD GRAINS } \\
\text { (CEREALS+PULSE }\end{array}$ & 174.13 & 160.31 & 141.13 & 129.18 & 118.71 & 104.28 \\
\hline & & & & & 107.79 & 104.43 \\
\hline Wheat & 172.18 & \begin{tabular}{|l|}
159.75 \\
\end{tabular} & 144.47 & 132.84 & 121.26 & 100.84 \\
\hline Pulses & 200.84 & 178.8 & 151.35 & 147.83 & 141.99 & 106.63 \\
\hline Fruits and vę & 163.02 & 143.61 & 131.93 & 124.12 & 108.38 & 106.11 \\
\hline Eggs, meat and fish & 184.2 & 140.76 & 122.56 & 116.47 & 110.98 & 103.54 \\
\hline minerals & 244.03 & 187.65 & 185.51 & 144.4 & 134.3 & 111.93 \\
\hline & 504.81 & 271.78 & 299.59 & 194.15 & 163.17 & 113.86 \\
\hline LPG & 121.7 & 112.34 & 115.24 & 106.1 & 106.1 & 106.1 \\
\hline Petrol & 134.82 & 116.72 & 130.1 & 119.26 & 124.6 & 109.85 \\
\hline Electricity (Domestic) & 113.23 & 107.38 & 104.88 & 103.73 & 100.87 & 99.18 \\
\hline Dairy produ & 150.38 & 132.99 & 121.02 & 114.75 & 102.58 & 99.4 \\
\hline Igar & 66.36 & 145.64 & 99.14 & 92.63 & 110.49 & 107.6 \\
\hline Textiles & 115.25 & 104.68 & 102.81 & 101.41 & 100.52 & 98.91 \\
\hline Paper & 123.08 & 118.13 & 115.39 & 110.82 & 107.2 & 102.62 \\
\hline Fertilizers and Pesticides & 114.02 & 108.26 & 107.03 & 106.02 & 104.28 & 101.81 \\
\hline Drugs and Medicines & 114.5 & 112.32 & 110.99 & 106.46 & 102.22 & 100.91 \\
\hline cement & 136.5 & 129.34 & 121.2 & 115.3 & 109.34 & 103.46 \\
\hline Steel and All & 142.95 & 136.66 & 137.11 & 121.01 & 109.88 & 105.55 \\
\hline Metal Products & 160.9 & 147.89 & 141.51 & 123.65 & 117.02 & 104.1 \\
\hline Gold & 275.78 & 228.3 & 188.08 & 150.07 & 142.84 & 102.27 \\
\hline Silver & 285.54 & 202.04 & 192.88 & 171.83 & 155.13 & 101.01 \\
\hline Automotives & 119.11 & 115.37 & 110.12 & 105.22 & 103.44 & 101.65 \\
\hline By-Cycles & 134.1 & 131.93 & 119.63 & 114.67 & 109.44 & 103.72 \\
\hline
\end{tabular}

And if we observe the trends of the very essential commodities as given in the table 6 , it is understood that very essential commodities like food grains, rice, wheat, pulses, vegetables, eggs, dairy products, sugar and bycycles which are consumed by poor and middle class by 
sparing major share of their income have higher rate of increase in their prices. But some goods like electricity, petrol, textiles, LPG, paper, fertilizers and pesticides have not that great increase but still almost at par with the inflation rate calculated. Similarly items like iron ore, minerals, cement, steel, metal products, gold. silver etc., which can indirectly influence the lives of many also have higher rate of increase in price than the all commodity WPI. That means the inflation rate calculated is not reflecting the real time situation of the market. This is all because of not giving proper weight-ages to the commodities and commodity groups as per their real price variations in the market. The present method of calculation of WPI and inflation are mostly in favor of the rich because they are not influenced by the increased prices of the essential commodities much and at the same time they are multiplying their money because investments, businesses and supportive policies mainly related to the manufactured products. This is indirectly increasing the gap between the rich and poor [3].

\section{CONCLUSION}

In this analysis, it is revealed surprisingly that though all the commodity prices are continually increasing irrespective of variations in inflation, the prices of primary articles and food grains are continually increasing at quite higher rate. This is not reflected by the WPI and inflation measurement of the existing method. It is well known fact that, for these basic needs only, major share of the income of poor and middle class people is spent. This means a continuous increase in burden on them. It is also observed that some commodity prices are varying in line with inflation and for some others no much variation is seen. From this study, it is felt that there is an immediate attention required to change the weight-ages given to various commodities in calculating the inflation to indicate reality.

\section{ACKNOWLEDGEMENTS}

This paper is incomplete without my sincere thanks to my husband, other family members, friends and teachers who helped and co-operated to complete this work.

\section{REFERENCES}

[1] Amith Gosh, "Inflation in India: knowing the right numbers" - an article published in http://knol.google.com/k/inflation\%20india.

[2] Publications of Planning Commission of India.

[3] Publications of Office of Economic Adviser, Govt. of India. 